\title{
Flora da Usina São José, Igarassu, Pernambuco: Chrysobalanaceae, Humiriaceae, Lacistemataceae e Trigoniaceae
}

Flora of Usina São José, Igarassu, Pernambuco: Chrysobalanaceae, Humiriaceae, Lacistemataceae and Trigoniaceae

\author{
Francione Gomes-Silva ${ }^{1,4}$, Arthur Macedo ${ }^{2}$,Edlley Pessoa ${ }^{3}$ \& Marccus Alves ${ }^{1}$
}

\begin{abstract}
Resumo
Malpighiales compreende 36 famílias com grande heterogeneidade morfológica e está representada por várias espécies na Mata Atlântica ao longo da costa brasileira. Este trabalho é parte da série de monografias taxonômicas de famílias ocorrentes em fragmentos de Mata Atlântica da Usina São José (USJ), Igarassu, Pernambuco. Aqui são apresentados os tratamentos de quatro famílias da ordem Malpighiales: Chrysobalanaceae, Humiriaceae, Lacistemataceae e Trigoniaceae. Coletas foram realizadas em seis fragmentos, entre 2009 e 2017, além de visitas a herbários. Foram reconhecidos nove taxa: Chrysobalanaceae está representada por seis espécies, e as demais famílias por uma espécie cada. As espécies no geral são amplamente distribuídas na América do Sul, com exceção de Couepia rufa, Moquilea tomentosa e Lacistema robustum, que são endêmicas da Mata Atlântica. Uma chave para espécies, descrições, comentários e ilustrações também são fornecidas.

Palavras-chave: Malpighiales, Mata Atlântica, taxonomia.
\end{abstract}

\begin{abstract}
Malpighiales comprises 36 families with large morphological heterogeneity and is represented by several species in the Atlantic rain forest along the Brazilian coast. This article is part of a series of taxonomic monographs of families occurring on fragments of Atlantic Forest from Usina São José (USJ), Igarassu, Pernambuco. Treatments to four families of Malpighiales are presented: Chrysobalanaceae, Humiriaceae, Lacistemataceae and Trigoniaceae. Fieldwork was conducted in six fragments, between 2009 and 2017, in addition to visits to herbaria. Nine taxa were found: Chrysobalanaceae is represented by six species, and the other families have a single species each. Most species are widely distributed in South America, except for Couepia rufa, Moquilea tomentosa and Lacistema robustum, which are endemic to the Atlantic Forest. A key to species, descriptions, comments and illustrations are also provided.
\end{abstract}

Key words: Malpighiales, Atlantic Forest, taxonomy.

\section{Introdução}

Malpighiales é monofilética, sustentada principalmente por dados moleculares (Soltis et al. 2000) e muitos de seus taxa possuem estigmas secos, exotégmen fibroso e folhas com margens dentadas, onde os dentes apresentam uma única nervura terminada em um ápice congesto e frequentemente decíduo (Judd et al. 2009). No entanto, a ordem é morfologicamente heterogênea e composta por cerca de 16.000 espécies, 716 gêneros e 36 famílias (APG IV 2016; Stevens 2017). São apresentadas aqui: Chrysobalanaceae R.Br., Humiriaceae Juss., Lacistemataceae Mart. e Trigoniaceae A. Juss., todas com centro de diversidade na região Neotropical, especialmente na América do Sul.

Chrysobalanaceae é pantropical, com 423 das suas 531 espécies ocorrendo nos Neotrópicos (Prance 2014). São geralmente árvores ou arbustos, caracterizados pelas estípulas, folhas

\footnotetext{
${ }^{1}$ Universidade Federal de Pernambuco, Depto. Botânica, Av. Prof. Moraes Rego 1235, Cidade Universitária, 50670-901, Recife, PE, Brasil.

${ }^{2}$ Universidade Federal Rural de Pernambuco, R. Dom Manoel de Medeiros s/n, Dois Irmãos, 52171-900, Recife, PE, Brasil.

3 Universidade Estadual do Maranhão, Pça. Duque de Caxias s.n., Morro do Alecrim, 65604-375, Caxias, Maranhão, Brasil.

${ }^{4}$ Autor para correspondência: cionesb@hotmail.com
} 
simples, alternas e flores períginas com estilete ginobásico (Prance 1972, 1989; Barroso 1991; Prance \& Sothers 2003a,b). Seus gêneros mais representativos são Hirtella L. (108 spp.), Licania Aubl. (ca. 100 spp.) e Couepia Aubl. (ca. 62 spp.) (Prance 2014; Sothers et al. 2016). No Brasil ocorrem 277 espécies distribuídas em todo o território nacional [Flora do Brasil 2020 (2017)], com centro de diversidade na Amazônia (Prance 2003; BFG 2015).

Humiriaceae é composta por oito gêneros e cerca de 60 espécies, distribuídas na América do Sul e Central, com uma espécie na costa africana (Bove 1997). São plantas lenhosas, com estames heterodínamos e filetes concrescidos, arranjados em um ou mais verticilos e disco nectarífero lobado (Sá Neto \& Lima 2003). Seus gêneros mais representativos são Vantanea Aubl. (16 spp.) e Humiriastrum (Urb.) Cuatrec. (12 spp.) (Stevens 2017). No Brasil ocorrem oito gêneros e 35 espécies distribuídas na Amazônia, Caatinga, Cerrado e Mata Atlântica (BFG 2015).

Lacistemataceae é neotropical, com dois gêneros e cerca de 15 espécies (Sleumer 1980; Stevens 2017). São plantas lenhosas, com flores pequenas arranjadas em racemos densos ou espigas, com corola ausente e um único estame (Sleumer 1980). No Brasil ocorrem 11 espécies dos dois gêneros, principalmente na Amazônia, Cerrado e Mata Atlântica (BFG 2015) e maior diversidade nas florestas úmidas das Regiões Norte, Sudeste e Sul (Marinho \& Amorim 2015).

Trigoniaceae é pantropical, com 28 espécies em cinco gêneros (Bittrich 2014). São reconhecidas pelas folhas simples, geralmente opostas, e flores papilionáceas obliquamente simétricas (Lleras 1978). Trigonia Aubl. é o gênero mais representativo com 24 espécies, sendo os demais monoespecíficos (Bittrich 2014; Stevens 2017). No Brasil ocorrem dois gêneros e 25 espécies, distribuídas na Amazônia, Caatinga, Cerrado, Mata Atlântica e Pantanal (BFG 2015).

As famílias aqui tratadas têm maior riqueza nas florestas úmidas tropicais, como a Amazônia e Mata Atlântica, que funcionam para muitas como centros de diversidade (Kubitzki 2014). Este estudo, parte de uma série de monografias previamente publicadas, objetivou inventariar e caracterizar morfologicamente as espécies de Chrysobalanaceae, Humiriaceae, Lacistemataceae e Trigoniaceae ocorrentes na Usina São José, agregando informações dessas famílias para a área e a Mata Atlântica ao norte do Rio São Francisco.

\section{Material e Métodos}

A Usina São José (USJ) abrange uma área de $280 \mathrm{~km}^{2}$ incluída nos municípios de Igarassu, Goiânia, Itaquitinga, Itapessuma, Abreu e Lima e Araçoiaba, sendo a maior parte de sua área concentrada no primeiro município (Trindade et al. 2008). Está inserida na porção norte do estado de Pernambuco e sua paisagem é constituída por cerca de 100 fragmentos florestais de tamanhos variados, cercados por plantações de cana-deaçúcar que revestem os tabuleiros, encostas e terraços fluviais da área (Buril et al. 2013). O clima é do tipo quente e úmido - As segundo Köppen (1948) -, com temperatura média anual em torno de $25^{\circ} \mathrm{C}$ e precipitação média de $1.687 \mathrm{~mm}$ anuais (Trindade et al. 2008).

Coletas foram realizadas em seis fragmentos (Piedade, Pezinho, Dedo de Deus, Macacos, Zambana e Chave), no período de dezembro de 2009 a abril de 2017, por meio de caminhadas exploratórias, seguindo as recomendações de Fidalgo \& Bononi (1984) para o processamento do material botânico. Os vouchers foram incorporados ao Herbário UFP e duplicatas enviadas aos herbários JPB, RB e CSTR (Universidade Federal de Campina Grande). Informações adicionais foram obtidas por meio de consulta a coleções da Flora da Usina São José, presentes nos acervos dos herbários IPA, JPB, PEUFR, UFP, UFRN e HST (Universidade Federal Rural de Pernambuco), siglas conforme Thiers (continuamente atualizado).

A identificação dos táxons se deu por meio de bibliografias especializadas (Prance 1972, 1989; Lleras 1978; Guimarães \& Miguel 1996; Prance \& Sothers 2003a, b; Sá Neto \& Lima 2003; Marinho $\&$ Amorim 2015). Adotou-se nesse trabalho a circunscrição proposta por Sothers et al. (2016) para o gênero Licania (Chrysobalanaceae). A caracterização morfológica baseou-se no proposto por Harris \& Harris (2000) e Prance (1972); para nervação foliar o proposto por Ash et al. (1999). A classificação dos habitats da Mata Atlântica segue Silva et al. (2008) e Pessoa \& Alves (2012), que a divide em áreas de encostas, borda, tabuleiros e sítios ripários (Fig. 1).

Informações sobre ecologia das espécies foram obtidas através de observações em campo e dos dados presentes nas etiquetas das exsicatas examinadas. As descrições das famílias foram baseadas nas espécies ocorrentes na área de estudo. Este trabalho segue a organização apresentada nas demais monografias sobre os principais grupos de 

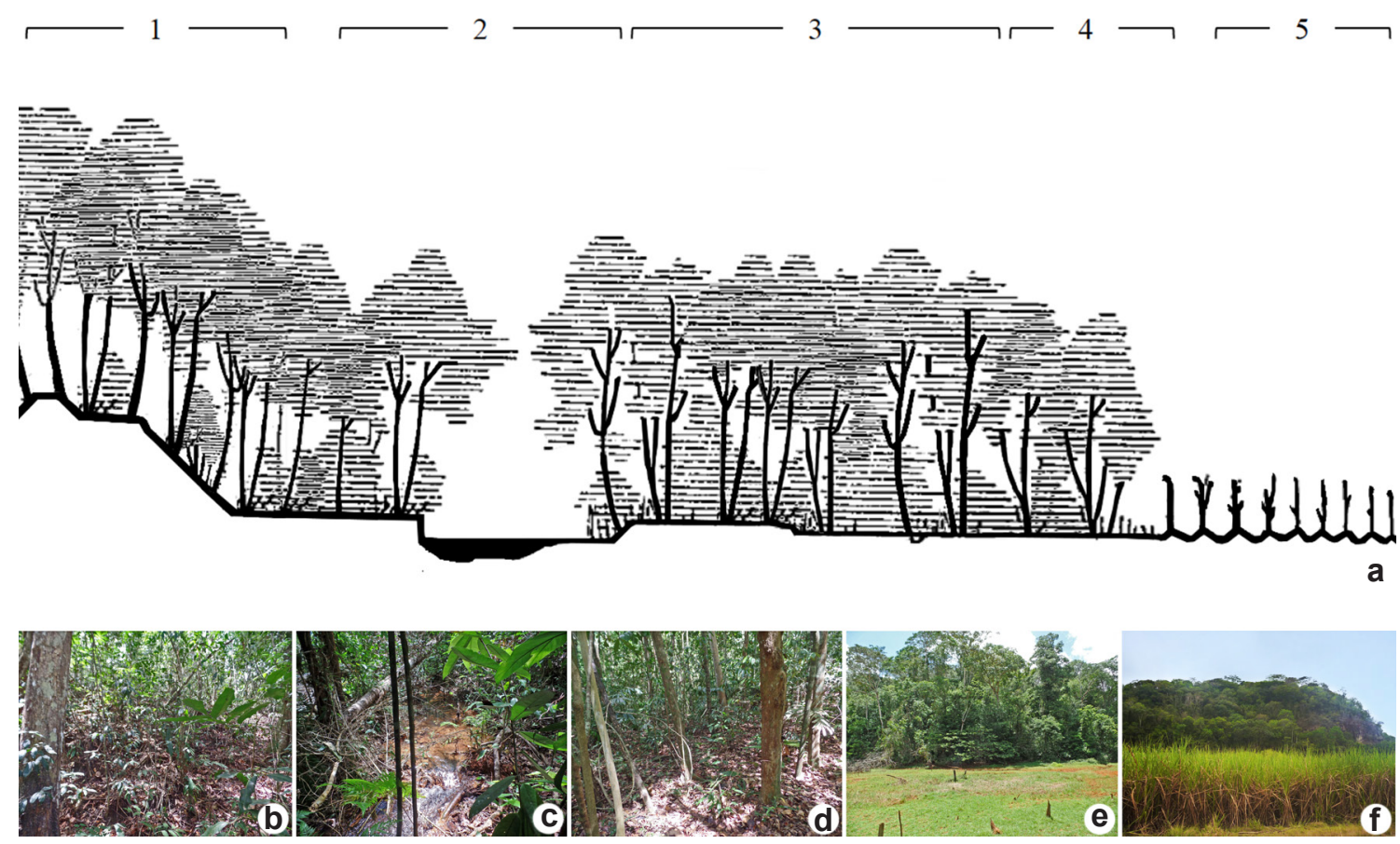

Figura 1 - a-f. Habitats da Mata Atlântica adotados para USJ - a. representação dos habitats; b,1. encostas (áreas inclinadas); c,2. sítios ripários (áreas alagadas ou sobre influências de cursos d'aguas); d,3. tabuleiros (áreas planas); e,4. borda (limite da floresta com a matriz de cana-de-açúcar); f,5. matriz canavieira.

Figure 1 - a-f. Atlantic Forest habitats adopted for USJ - a. representation of habitats; b,1. slopes (inclined areas); c,2. riparian sites (flooded areas or affected by watercourses); d,3. tabuleiros (plane areas); e,4. edge (forest boundary with sugar-cane matrix); f,5. sugarcane matrix.

Angiospermas da flora da Usina São José (e.g., Amorim \& Alves 2011; Buril \& Alves 2011; Pessoa \& Alves 2012; Melo et al. 2013; Buril et al. 2014; Amorim et al. 2016; Luna et al. 2016, entre outros).

\section{Resultados e Discussão}

Foram encontradas nove espécies distribuídas em oito gêneros. A família Chrysobalanaceae foi a mais representativa com seis espécies: Hirtella racemosa Lam., H. bicornis Mart. \& Zucc., Leptobalanus octandrus (Hoffmanns. ex Roem. \& Schult.) Sothers \& Prance e Licania kunthiana Hook.f. com ampla distribuição na região Neotropical; Couepia rufa Ducke e Moquilea tomentosa Benth. restritas ao Brasil e endêmicas da Mata Atlântica (Prance \& Sothers 2003a, b; Sothers et al. 2016). No entanto, a última é amplamente cultivada em todo o Brasil para a arborização urbana.

Hirtella sprucei Benth. ex Hook.f. previamente listada por Alves et al. (2013) para a Usina São José, não foi incluída neste tratamento, pois o voucher $[J$. Gomes 328 (IPA)] indicado como pertencente a essa espécie não foi encontrado e nenhuma das amostras analisadas provenientes da área de estudo se encaixa na circunscrição de H. sprucei.

Em Pernambuco, a família Chrysobalanaceae está registrada por 13 espécies (BFG 2015), estando presente na USJ cerca de $50 \%$ da diversidade da família no estado. Quando comparado com outros levantamentos realizados na Mata Atlântica pernambucana, a área se destaca por sua expressiva riqueza, uma vez que os estudos de Sacramento et al. (2007), Pessoa et al. (2009), Melo et al. (2016) e Ferreira et al. (2016) registraram entre uma e três espécies. $\mathrm{O}$ valor obtido se aproxima do número encontrado por Zickel et al. (2007) no levantamento de espécies ocorrentes em áreas de restinga, onde foram listadas sete espécies, três delas ocorrentes na USJ. Segundo Prance (2003), embora a família ocorra em diversos habitats, as florestas de terras baixas são mais diversas, o que explica o observado na área de estudo. 
Para as demais famílias foram registradas uma espécie de cada: Sacoglottis mattogrossensis Malme (Humiriaceae); Lacistema robustum Schnizl. (Lacistemataceae) e Trigonia nivea Cambess. (Trigoniaceae). Dessas apenas $L$. robustum tem distribuição restrita ao domínio da Mata Atlântica (BFG 2015) e na USJ foi encontrada em apenas um fragmento. Sacoglottis mattogrossensis e T. nivea têm distribuição ampla na América do Sul.

\section{Chave de identificação das espécies de Chrysobalanaceae, Humiriaceae, Lacistemataceae e Trigoniaceae ocorrentes na Usina São José, Igarassu, Pernambuco}

1. Lianas; folhas opostas; corola zigomorfa (papilionácea)

9. Trigonia nivea (Trigoniaceae)

1'. Árvores ou arbustos; folhas alternas; corola actinomorfa ou ausente

2. Folhas com nervação camptódroma ou cladódroma; inflorescência em espiga ou pleiocásio; hipanto ausente; estilete terminal

3. Lenticelas inconspícuas; folhas glabrescentes a estrigosas, camptódromas; inflorescência em espiga; corola ausente; estames 2, fusionados até o ápice; fruto cápsula

\section{Lacistema robustum (Lacistemataceae)}

3'. Lenticelas conspícuas; folhas glabras, cladódromas; inflorescência em pleiocásio; corola presente; estames 10, fusionados na base; fruto drupa

7. Sacoglottis mattogrossensis var. mattogrossensis (Humiriaceae)

2'. Folhas com nervação broquidódroma; inflorescência em racemo ou panícula; hipanto presente; estilete ginobásico Chrysobalanaceae

4. Ovário inserido no centro do receptáculo ou próximo a ele

5. Pecíolos eglandulosos; estames inclusos, distribuídos lateralmente em torno do ovário; estaminódios presentes 5. Licania kunthiana

5'. Pecíolos glandulosos; estames exsertos, distribuídos uniformemente em torno do ovário; estaminódios ausentes

6. Folhas ovadas, elípticas a obovadas, coriáceas; corola ausente; estames 8 a 10 ... 4. Leptobalanus octandrus subsp. octandrus

6'. Folhas oblongas, elípticas, raramente obovadas, cartáceas; corola presente; estames 25 a 30

6. Moquilea tomentosa

4'. Ovário inserido na borda do receptáculo

7. Lâmina foliar 12,5-16,5 cm compr., margem revoluta; brácteas caducas; estames ca. 60 1. Couepia rufa

7'. Lâmina foliar 2,2-11,2 cm compr., margem plana; brácteas persistentes; estames de 5 a 6

8. Árvores; folhas cartáceas; inflorescência panícula; hipanto campanulado; brácteas e bractéolas eglandulosas 2. Hirtella bicornis

8'. Arvoretas, arbustos ou subarbustos; folhas coriáceas a subcoriáceas; inflorescência racemo; hipanto cilíndrico a estreito-campanulado; brácteas e bractéolas glandulosas 3. Hirtella racemosa

Chrysobalanaceae R. Br.

Árvores, arbustos ou subarbustos, ramos pubescentes, pubérulos, tomentosos a esparsamente hirsutos quando jovens a glabrescentes ou glabros com a idade, lenticelados ou não. Folhas simples, alternas, inteiras, margem plana ou revoluta, nervação broquidódroma; estípulas 2 , axilares, eglandulosas, persistentes a caducas; pecíolo cilíndrico a canaliculado, glanduloso ou eglanduloso. Inflorescência em panícula ou racemo, terminal ou axilar; brácteas e bractéolas persistentes a caducas, glandulosas ou eglandulosas. Flores períginas, pediceladas a sésseis; hipanto presente, lobos do cálice agudos a arredondados; disco nectarífero presente revestindo o receptáculo, anelar ou tubular em sua abertura; corola presente ou ausente, pétalas não diferenciadas; estames 5 a muitos, inseridos lateralmente ou uniformemente na margem do receptáculo, estaminódios ausentes ou opostos aos estames; filetes livres, filiformes, 
glabros, exsertos ou inclusos; anteras rimosas, dorsifixas; ovário súpero, inseridos na borda, centro ou próximo ao centro do receptáculo; 1-locular, 2-ovulado; estilete filiforme, ginobásico, estigma truncado. Fruto drupa.

Conepia Aubl.

1. Conepia rufa Ducke, Arch. Mus. Rio de Janeiro 22: 66. 1919.

Fig. 2a-c

Árvores, 6-10 m alt.; ramos tomentosos a pubescentes quando jovens, glabrescentes quando maduros, levemente lenticelados. Estípulas 1,3-1,5 $\times 0,2 \mathrm{~cm}$, estreito-lanceoladas, glabras, caducas; pecíolo $0,8-1 \mathrm{~cm}$ compr., canaliculado, tomentoso, eglanduloso; lâmina foliar 12,5-16,5 × 6-8,5 cm, elíptica a ovada, coriácea a subcoriácea, face adaxial glabra, abaxial lanosa, nervura primária glabra na face adaxial, tomentosa a pubescente na abaxial, secundárias glabras na face adaxial, tomentosas na abaxial, 13-17 pares, margem revoluta, base subcordada a cordada, ápice arredondado a curto acuminado, acúmen $0,1 \mathrm{~cm}$ compr. Inflorescência panícula, terminal; raque tomentosa, acinzentada a amarelada; brácteas ca. $0,3 \times 0,3 \mathrm{~cm}$, triangulares, caducas, pubescentes, eglandulosas, bractéolas $0,18-0,2 \times 0,15-0,2 \mathrm{~cm}$, lanceoladas, caducas, pubescentes, eglandulosas. Flores pediceladas, pedicelo $0,5-0,7 \mathrm{~cm}$ compr., eglanduloso; hipanto turbinado, adaxialmente glabro, abaxialmente puberulento; lobos do cálice $0,7-0,9 \mathrm{~cm}$ compr., arredondados a agudos, pubescentes; corola actinomorfa, pétalas $0,6-0,8 \times 0,5-0,6 \mathrm{~cm}$, ovadas, ápice arredondado, ciliadas; estames ca. 60 , exsertos, inseridos uniformemente em torno do ovário, estaminódios ausentes; filetes 1-1,6 cm compr.; ovário ca. $0,5 \times 0,4 \mathrm{~cm}$, arredondado, inserido na borda do receptáculo, densamente pubescente; estilete 1,4-1,5 cm compr., híspido na base a glabro no ápice. Fruto 7-8 cm compr., ovado a oblongo, epicarpo glabrescente.

Material examinado: Mata de Piedade, 25.I.2017, F. Gomes-Silva 256 (CSTR, JPB, UFP).

Material adicional examinado: BRASIL. ALAGOAS: Ibateguara, Coimbra, 16.X.2002, fr., M. Oliveira \& A.A. Grilo 1135 (UFP). PERNAMBUCO: Igarassu, Refúgio Ecológico Charles Darwin, 6.XII.96, fl., M.F.A. Lucena \& M. Falcão 238 (PEUFR, UFP).

Endêmica da Mata Atlântica, ocorre nas regiões Nordeste (Bahia e Pernambuco) e Sudeste (Minas Gerais) do Brasil em florestas úmidas (Prance \& Sothers 2003b). Na USJ foi encontrada na borda dos fragmentos e interior da mata, em áreas de tabuleiros ou encostas. Pode ser diferenciada das demais espécies da família na área pelas folhas elípticas a ovadas com 12,5 a 16,5 cm de compr. (quando jovens suas folhas podem chegar a cerca de $45 \mathrm{~cm}$ de compr.), margens revolutas e face abaxial lanosa, suas flores são grandes quando comparadas com as demais Chrysobalanaceae, apresentando numerosos estames (ca. 60).

\section{Hirtella L.}

2. Hirtella bicornis Mart. \& Zucc., Abh. Math.Phys. Cl. Königl. Bayer. Akad. Wiss. 1: 377. 1832.

Fig. 2d-f

Árvores, 3-6 m alt.; ramos pubescentes a espaçadamente pubescentes quando jovens, glabros quando maduros, lenticelados. Estípulas $0,15-0,3 \times 0,05-0,07 \mathrm{~cm}$, lineares, pubescentes, persistentes; pecíolo 0,05-0,15 cm compr., cilíndrico, pubescente, eglanduloso; lâmina foliar 2,7-6,8 × 1,4-4 cm, ovada a elíptica, cartácea, face adaxial glabrescente a glabra, abaxial espaçadamente pubescente, nervura primária glabra na face adaxial, pubescente a espaçadamente pubescente na abaxial, secundárias glabras na face adaxial, glabrescentes a glabras na abaxial, 8-10 pares, margem plana, base arredondada a cuneada, ápice acuminado, acúmen 0,5-1,1 cm compr. Inflorescência panícula, axilar; raque pubescente, verde-acinzentada; brácteas $0,1-0,2 \times 0,05 \mathrm{~cm}$, triangulares, persistentes, pubescentes, eglandulosas, bractéolas $0,05-0,1 \times$ ca. $0,05 \mathrm{~cm}$, lanceoladas, persistentes, pubescentes, eglandulosas. Flores pediceladas, pedicelo 0,2-1,5 cm compr., eglanduloso; hipanto campanulado, adaxialmente glabrescente, abaxialmente pubescente; lobos do cálice $0,2-0,4 \mathrm{~cm}$ compr., agudos a arredondados, face adaxial tomentosa, abaxial pubescente; corola actinomorfa, pétalas $0,3-0,4 \times 0,3-0,35 \mathrm{~cm}$, ovais, ápice arredondado a retuso, glabras; estames 6 , exsertos, inseridos lateralmente em torno do ovário, estaminódios opostos aos estames; filetes $0,8-1,1 \mathrm{~cm}$ compr.; ovário ca. $0,1 \times 0,1 \mathrm{~cm}$, ovado a orbicular, inserido na borda do receptáculo; estilete 1-1,2 cm compr., híspido próximo à base a glabro no ápice; estigma truncado. Fruto 1,3-1,5 × 0,5-0,7 cm, elipsoide, epicarpo glabro.

Material examinado: Granja São Luiz, 11.IX.1969, fl., D. Andrade-Lima 69-5595 (IPA, NY).

Material adicional examinado: BRASIL. PERNAMBUCO: Cabo de Santo Agostinho, praia do Cabo, 2.XII.1971, fl., I.V. Leãol64 (UFP); área projeto Suape, 19.X.1977, fl. e fr., D. Andrade-Lima \& J.T. Medeiros-Costa 33 (IPA). 

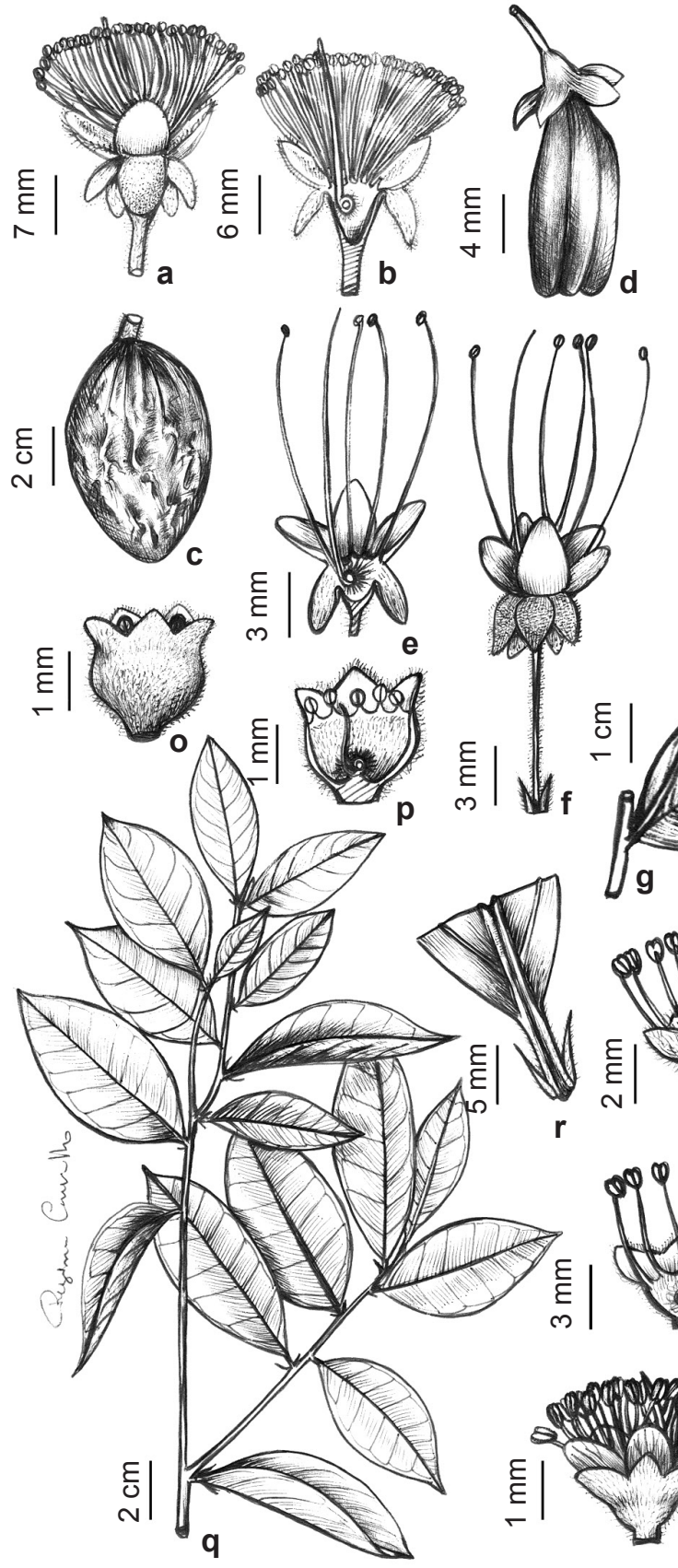

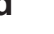


Ocorre da Colômbia às Guianas, na Amazônia Peruana e no Brasil, em quase todos os estados da Região Norte, no Mato Grosso, Pernambuco (Prance \& Sothers 2003b) e Bahia (Asprino \& Amorim 2016). Registrada para Granja São Luiz, área de Mata Atlântica, situada nas proximidades da USJ e por essa razão aqui incluída. Pode ser diferenciada de $H$. racemosa pelas folhas cartáceas (vs. coriáceas a subcoriáceas), inflorescência em panícula ( $v s$. inflorescência em racemo) com brácteas e bractéolas eglandulosas (vs. glandulosas) e hipanto campanulado ( $v s$. cilíndrico a estreitocampanulado).

\section{Hirtella racemosa Lam., Encycl. 3: 133. 1789.}

Fig. $2 \mathrm{~g}-\mathrm{j}$

Arvoretas, arbustos a subarbustos, $2-5 \mathrm{~m}$ alt.; ramos pubescentes a puberulentos quando jovens, glabros quando maduros, lenticelados. Estípulas $0,3-0,6 \times 0,1 \mathrm{~cm}$, lineares, pubescentes, persistentes; pecíolo 0,1-0,2 cm compr., cilíndrico, pubescente, eglanduloso; lâmina foliar 2,2-11,2 $\times$ 1,2-5,4 cm, elíptica, oblongo-lanceolada, coriácea a subcoriácea, faces adaxial e abaxial pubescentes, glabrescentes a glabras, nervura primária hirsuta em ambas as faces, secundárias glabrescentes na face adaxial, espaçadamente hirsutulosas na face abaxial, 6-9 pares, margem plana, base subcordada a arredondada ou cuneada, ápice acuminado a agudo, acúmen 0,25-1,2 cm compr. Inflorescência racemo, terminal ou axilar; raque pubescente a puberulenta, amarronzada; brácteas $0,1-0,2 \times$ $0,05 \mathrm{~cm}$, lanceoladas, persistentes, pubescentes, com glândulas sésseis a eglandulosas, bractéolas $0,05-0,1 \times$ ca. $0,03 \mathrm{~cm}$, lanceoladas, persistentes, pubescentes, com glândulas sésseis no ápice e/ou na base. Flores pediceladas, pedicelo $0,5-0,9 \mathrm{~cm}$ compr., eglanduloso; hipanto cilíndrico a estreitocampanulado, adaxialmente glabro, abaxialmente puberulento; lobos do cálice $0,2-0,3 \mathrm{~cm}$ compr., agudos, face adaxial serícea, abaxial puberulenta; corola actinomorfa, pétalas $0,4-0,5 \times 0,3-0,4$ $\mathrm{cm}$, ovadas a arredondadas, ápice arredondado a emarginado, glabras; estames 5-6, exsertos, inseridos lateralmente ao ovário, estaminódios opostos aos estames; filetes $0,9-1 \mathrm{~cm}$ compr.; ovário ca. $0,1 \times 0,1 \mathrm{~cm}$, orbicular, inserido na borda do receptáculo, densamente pubescente; estilete $1-1,1$ $\mathrm{cm}$ compr., piloso a híspido na base a glabro no ápice. Fruto 1,2-1,3 cm compr., elipsoide, epicarpo espaçadamente pubescente.

Material examinado selecionado: Córrego do Urubu, 1.IV.2008, fl., L.M. Nascimento 679 (UFP); Dedo de Deus,
26.X.2016, fl. e fr., F. Gomes-Silva 239 (CSTR, JPB, UFP); Fragmento Chave, 18.XII. 2009, fl., D. Cavalcante \& E. Pessoa 37 (UFP); Mata de Cruzinha, 30.X.2008, fl., J.A.N. Sousa 263 (UFP); Mata dos Macacos, 28.XI.2007, fl., A. Melo et al. 175 (HVASF, UFP); 15.V.2004, bot. e fl., I.M.M.S. Silva et al. 326 (UFP); 16.IV.2008, fl., J. Irapuan et al. 17 (UFP); Mata de Pezinho, 11.I.2008, fl., $A$. Alves-Araújo et al. 821 (UFP); 8.III.2009, fl. e fr., J.A.N. Souza 365 (UFP); Mata de Piedade, 25.I.2017, fl. e fr., F. Gomes-Silva 255 (CSTR, JPB, UFP); 28.XI.2007, fl., A. Melo et al. 156 (UFP); Mata de Zambana, 26.X.2016, fr., F. Gomes-Silva 237 (CSTR, JPB, UFP).

Amplamente distribuída na região Neotropical, sendo uma das espécies mais comuns de Chrysobalanaceae, ocorre desde florestas a campos abertos (Prance 1972). Há registro no Nordeste para a Bahia, Ceará, Maranhão, Paraíba, Pernambuco e Sergipe (BFG 2015). Apresenta grande variabilidade morfológica, sendo reconhecidas três variedades diferenciadas pelo tamanho da lâmina foliar, forma da base e ápice e pelo formato e disposição de glândulas nas brácteas e bractéolas (Prance \& Sothers 2003b). Mas devido à sobreposição desses caracteres no material examinado, essas categorias infraespecíficas não foram adotadas para este táxon.

Hirtella racemosa pode ser diferenciada das demais espécies de Chrysobalanaceae registradas neste trabalho pelas flores com brácteas e bractéolas glandulosas e hipanto cilíndrico a estreitocampanulado. As diferenças entre esta espécie e H. bicornis foram apresentadas no comentário anterior. Coletada em vários fragmentos da USJ, principalmente em áreas de bordas, com flores e frutos em praticamente todos os meses do ano.

\section{Leptobalanus (Benth.) Sothers \& Prance}

4. Leptobalanus octandrus (Hoffmanns. ex Roem. \& Schult.) Sothers \& Prance subsp. octandrus, Kew Bull. 71: 58. 2016.

Fig. 2k-n

Árvores a arvoretas, 4-6 m alt.; ramos velutinos a pubérulos quando jovens, glabros quando maduros, lenticelas inconspícuas. Estípulas $0,3-0,4 \times 0,1 \mathrm{~cm}$, lineares, hirsutas, persistentes; pecíolo $0,2-0,6 \mathrm{~cm}$ compr., cilíndrico, hirsutuloso, tomentoso a glabrescente, um par de glândulas sésseis próximas à base da folha na face abaxial, geralmente obscurecidas pelo indumento; lâmina foliar 3,4-9,6 × 1,5-3,7 cm, ovada, elíptica a obovada, coriácea, face adaxial glabra, abaxial lanosa a glabra, nervuras primária e secundárias glabras em ambas as faces, 8-12 pares, margem plana, base subcuneada a cuneada, raro arredondada, ápice acuminado, raro obtuso ou agudo, acúmen 0,2-0,7 cm compr. Inflorescência panícula, axilar 
ou terminal; raque pubescente, amarelada; brácteas $0,2-0,3 \times 0,1-0,3 \mathrm{~cm}$, triangulares, persistentes, pubescentes, eglandulosas, bractéolas ca. $0,05 \times$ $0,03 \mathrm{~cm}$, triangulares, persistentes, pubescentes, eglandulosas. Flores sésseis a pediceladas, pedicelo ca $0,1 \mathrm{~cm}$ compr., eglanduloso; hipanto campanulado, adaxialmente viloso, abaxialmente tomentoso; lobos do cálice $0,15-0,17 \mathrm{~cm}$ compr., agudos, tomentosos em ambas as faces; corola ausente; estames 8-10, exsertos, inserido uniformemente em torno do ovário, estaminódios ausentes; filetes $0,4-0,5 \mathrm{~cm}$ compr.; ovário $0,1 \times 0,1 \mathrm{~cm}$, orbicular, inserido no centro do receptáculo, viloso, estilete $0,4-0,6 \mathrm{~cm}$ compr., viloso na base a glabro no ápice. Fruto 1,5-2,1 cm compr., globoso a elipsoide, epicarpo glabro.

Material examinado: Mata de Macacos, 21.XI.2002, I.M.M.S. Silva et al. 55 (PEUFR); Mata de Marezinha, 9.I.2009, fr., L.V. Cunha 352 (HST); Mata de Piedade, 25.I.2017, fr., F. Gomes-Silva 258 (CSTR, JPB, UFP); Mata de Zambana, 4.IX.2007, fl., A. Melo et al. 130 (IPA, UFP).

Ocorre do Norte da América do Sul ao Sudeste do Brasil em florestas de terra firme, áreas alagadas, savanas e matas ciliares (Prance \& Sothers 2003a); é encontrada em todos os estados do Nordeste (BFG 2015). Sothers et al. (2016) reconhecem três subespécies para $L$. octandrus, mas apenas a subespécie típica ocorre na USJ, encontrada principalmente em bordas de fragmentos. Pode ser diferenciado dos demais táxons de Chrysobalanaceae da USJ pelos pecíolos com um par de glândulas sésseis próximas à base da folha, visíveis na face abaxial e geralmente obscurecidas pelo indumento, folhas coriáceas ovadas, elípticas, às vezes obovadas, inflorescências em panículas com flores pequenas, apétalas e com 8 a 10 estames exsertos.

\section{Licania Aubl.}

5. Licania kunthiana Hook.f. in Mart., Fl. bras. 14(2): 16. 1867.

Fig. 2o-r

Árvores a arvoretas, 2-7,5 m alt.; ramos pubérulos quando jovens, glabrescentes quando maduros, lenticelados. Estípulas 0,2-0,6 $\times$ 0,05-0,08 cm, lineares, pubérulas, pubescentes a glabrescentes, persistentes, geralmente adnadas ao pecíolo; pecíolo 0,4-0,7 cm compr., cilíndrico a levemente canaliculado, pubescente a glabrescente, eglanduloso; lâmina foliar 2,5-15 × 1,7-6 cm, elíptica, oblongo-lanceolada, raramente obovada ou ovada, subcartácea a membranácea, face adaxial glabra, abaxial tomentosa, nervura primária glabra na face adaxial, glabescente na abaxial, secundárias glabras na face adaxial, tomentosas na abaxial, 7-10 pares, margem plana, base cuneada a subcuneada ou arredondada, ápice acuminado, raro arredondado, retuso ou emarginado, acúmen 0,1-1,6 cm compr. Inflorescência panícula, axilar ou terminal; raque pubescente, cinza; brácteas ca. 0,05 $\times 0,02 \mathrm{~cm}$, triangulares, persistentes, pubescentes, eglandulosas, bractéolas $0,01 \times 0,01-0,02 \mathrm{~cm}$, triangulares, persistentes, pubescentes, eglandulosas. Flores sésseis, eglandulosas; hipanto campanulado, adaxialmente pubescente, abaxialmente tomentoso; lobos do cálice 0,04-0,05 cm compr., agudos, tomentosos em ambas as faces; corola ausente; estames 5, inclusos, inseridos lateralmente em torno do ovário, estaminódios opostos aos estames; filetes 0,01-0,02 cm compr.; ovário ca. 0,04 × 0,04 $\mathrm{cm}$, orbicular, inserido no centro do receptáculo ou próximo a ele, densamente pubescente; estilete 0,1-0,17 cm compr., lanoso na base a glabro no ápice. Fruto 2,5-5 cm compr., oblongo, epicarpo glabro.

Material examinado: Mata de Macacos, 27.VII.2005, P.P. Oliveira et al. 52 (PEUFR); 7.IV.2003, I.M.M.S. Silva et al. 56 (PEUFR); 4.VII.2005, H.C.H. Silva \& J.S. Gomes 31 (PEUFR); Mata de Piedade, 25.I.2017, fr., F. GomesSilva 257 (CSTR, JPB, UFP); 4.XI.2003, J.S. Gomes \& H.C.H. Silva 44 (PEUFR).

Material adicional examinado: BRASIL. PERNAMBUCO: Recife, Mata de Dois Irmãos, 1.XII.1964, fl., G. Teixeira 2573 (HUCPE, HST, IPA); 9.XI.64, bot. e fl., S. Tavares 1208 (HST, IPA).

Ocorre da Costa Rica à América do Sul, até o estado de São Paulo, em florestas ombrófilas, florestas de terra firme, matas ciliares, cerrados e florestas secundárias (Prance \& Sothers 2003a). No Nordeste é registrada para Bahia, Maranhão, Pernambuco e Sergipe (BFG 2015). Na USJ foi encontrada em áreas de borda e encosta no interior dos fragmentos. Pode ser diferenciada pelas folhas elípticas, oblongo-lanceoladas, raramente obovadas ou ovadas, subcartáceas a membranáceas, com inflorescências em panículas de flores pequenas, com 0,1 a $0,3 \mathrm{~cm}$ compr., sem pétalas, com 5 estames inclusos, distribuídos lateralmente em torno do ovário.

Moquilea Aubl.

6. Moquilea tomentosa Benth., J. Bot. (Hooker) 2: 215. 1840.

Fig. 2s-v

Árvores, 6-12 m alt.; ramos lanosos, tomentosos, pubescentes a vilosos quando jovens, glabros quando maduros, lenticelados. Estípulas 0,4-0,7 × 0,08-0,1 cm, lineares, pubescentes, subpersistentes; pecíolo 0,4-0,6 cm compr., cilíndrico a canaliculado, lanoso, com glândulas sésseis visíveis na face adaxial, geralmente 
obscurecidas pelo indumento; lâmina foliar 5-11,5 × 1,7-4 cm, oblonga, elíptica, raramente obovada, cartácea, face adaxial glabra, aracnoide ou pulverulenta, abaxial lanosa a glabrescente, nervuras primária e secundárias pulverulentas a glabrescentes, 12-16 pares, margem plana, base cuneada, ápice acuminado, acúmen $0,2-0,3 \mathrm{~cm}$ compr. Inflorescência racemo ou panícula, axilar ou terminal; raque pubescente, cinza; brácteas $0,1-0,2 \times 0,1-1,5 \mathrm{~cm}$, triangulares, persistentes, glabrescentes, eglandulosas, bractéolas $0,02-0,04$ $\times 0,05-0,09 \mathrm{~cm}$, lanceoladas, caducas, pubescentes, eglandulosas. Flores subsésseis a pediceladas, pedicelo ca. $0,1 \mathrm{~cm}$ compr., eglanduloso; hipanto campanulado, adaxialmente lanoso, abaxialmente puberulento; lobos do cálice ca. 0,2 cm compr., agudos, face adaxial glabra a glabrescente no ápice, abaxial tomentosa; corola actinomorfa, pétalas $0,2-0,25 \times 0,25-0,3 \mathrm{~cm}$, ovadas a orbiculares, glabras; estames 25-30, exsertos, inseridos uniformemente em torno do ovário, estaminódios ausentes; filetes $0,3-0,4 \mathrm{~cm}$ compr.; anteras rimosas; ovário ca. $0,06 \times 0,06 \mathrm{~cm}$, ovado, lanoso, inserido no centro do receptáculo; estilete 0,4-0,5 cm compr., lanoso. Fruto 5-6,5 cm compr., elipsoide a oblongo, epicarpo tomentoso a glabro. Material examinado: Portaria da USJ, 26.IV.2017, F. Gomes-Silva 300 (UFP).

Material adicional examinado: BRASIL. PERNAMBUCO: Recife, Campus da UFPE, 14.I.2017, fr., F. Gomes-Silva 250 (CSTR, JPB, UFP); Parque Dois Irmãos, 18.IX.2000, fl., T. Costa Lima 53 (HST).

Nativa da Mata Atlântica brasileira, ocorre em restingas e florestas; atualmente é amplamente cultivada em todo o Brasil e empregada principalmente na arborização de cidades (Prance \& Sothers 2003a). Foi encontrada na entrada da USJ. Diferencia-se das demais espécies pelas folhas geralmente oblongas com indumento pulverulento em ambas as faces, inflorescência em racemo ou panícula, flores pequenas com 25 a 30 estames exsertos distribuídos uniformemente em torno do ovário.

Humiriaceae Juss.

Sacoglottis Mart.

7. Sacoglottis mattogrossensis Malme var. mattogrossensis, Arkiv. Bot. 22 (7): 9. 1928.

Fig. 3a-f

Árvores a arbustos, ca. $10 \mathrm{~m}$ alt.; ramos glabros, lenticelas conspícuas. Folhas simples, alternas; estípula 1, intrapeciolar, $0,08-0,1 \times \mathrm{ca}$. $0,1 \mathrm{~cm}$, foliar, glabra, caduca; pecíolo $0,2-0,7 \mathrm{~cm}$ compr., cilíndrico, glabro, eglanduloso; lâmina foliar 4,3-15,5 × 2,1-5,2 cm, elíptica a oblonga, membranácea, glabra, nervação cladódroma, nervuras secundárias 9-14 pares, margem inteira a serreada, base cuneada a arredondada, ápice acuminado, acúmen 1,1-1,5 cm compr. Inflorescência pleiocásio, axilar; raque pubescente, amarronzada; brácteas e bractéolas $0,05-0,12 \times$ $0,1-0,15 \mathrm{~cm}$, triangular-foliáceas, persistentes, glabras, eglandulosas. Flores pediceladas, pedicelo 0,2-0,3 cm compr., eglanduloso; hipanto ausente; sépalas $0,08-0,1 \mathrm{~cm}$ compr., triangulares, glabras; disco nectarífero na base do ovário; corola actinomorfa, pétalas lanceoladas, $0,3-0,38 \times$ $0,1-0,12 \mathrm{~cm}$, glabras; estames 10 , exsertos, parcialmente fusionados na base, formando uma corona estaminal, estaminódios ausentes; filetes 0,29-0,38 cm compr., linear-planos, glabros; anteras rimosas; ovário $0,1-0,12 \times 0,08-0,1 \mathrm{~cm}$, orbicular, 5-locular, glabro; 1-ovulado; estilete terminal, ca. 0,3 cm compr., glabro, estigma inteiro. Fruto drupa, 0,53-0,89 × 0,56-0,88 cm compr., globoso, glabro, desenvolvendo-se dentro da corona de estames.

Material examinado: Mata Zambana, 14.II.2008, fl. e fr., A. Alves-Araújo \& J. Marques 856 (HUEFS, UFP); Mata dos Macacos, 7.V.2003, I.M.M.S. Silva et al. 71 (PEUFR); 7.X.2005, A.P.P. Oliveira et al. 87 (PEUFR); Mata do Engenho Cruzinha, 25.III.2004, H.C.H. Lucena \& J.S. Gomes 337 (PEUFR); Mata de Piedade, 1.IV.2004, K. Rocha \& S.G. Freire 106 (PEUFR).

Material adicional examinado: BRASIL. PERNAMBUCO: Cabo de Santo Agostinho, Distrito de Ponte dos Carvalhos, Restinga da Praia do Paiva, 25.IX.1997, fl. e fr., A. Sacramento 162 (PEUFR).

Ocorre na Colômbia e no Brasil (Cuatrecasas 1961). É amplamente distribuída no país, com exceção da Região Sul (BFG 2015). No Nordeste está citada para Paraíba, Pernambuco e Piauí (Sá Neto \& Lima 2003; BFG 2015). Na USJ ocorre no interior dos fragmentos florestais, sendo menos comum na borda e em áreas de encosta. É reconhecida entre as espécies aqui tratadas pela corona estaminal e fruto globoso que se desenvolve dentro da corona.

\section{Lacistemataceae Mart. \\ Lacistema Sw.}

8. Lacistema robustum Schnizl. in Mart., Fl. bras. 4(1): 281. 1857.

Fig. 3g-j

Árvores, arvoretas a arbustos, ca. $10 \mathrm{~m}$ alt.; ramos glabros, lenticelas inconspícuas. Folhas simples, alternas; estípulas não vistas; pecíolo $0,7-1$ $\mathrm{cm}$ compr., cilíndrico, glabrescente, eglanduloso; lâmina foliar 4,5-12,6 × 2,3-5,7 cm, elíptica a obovada, raro oblonga, membranácea, face adaxial 


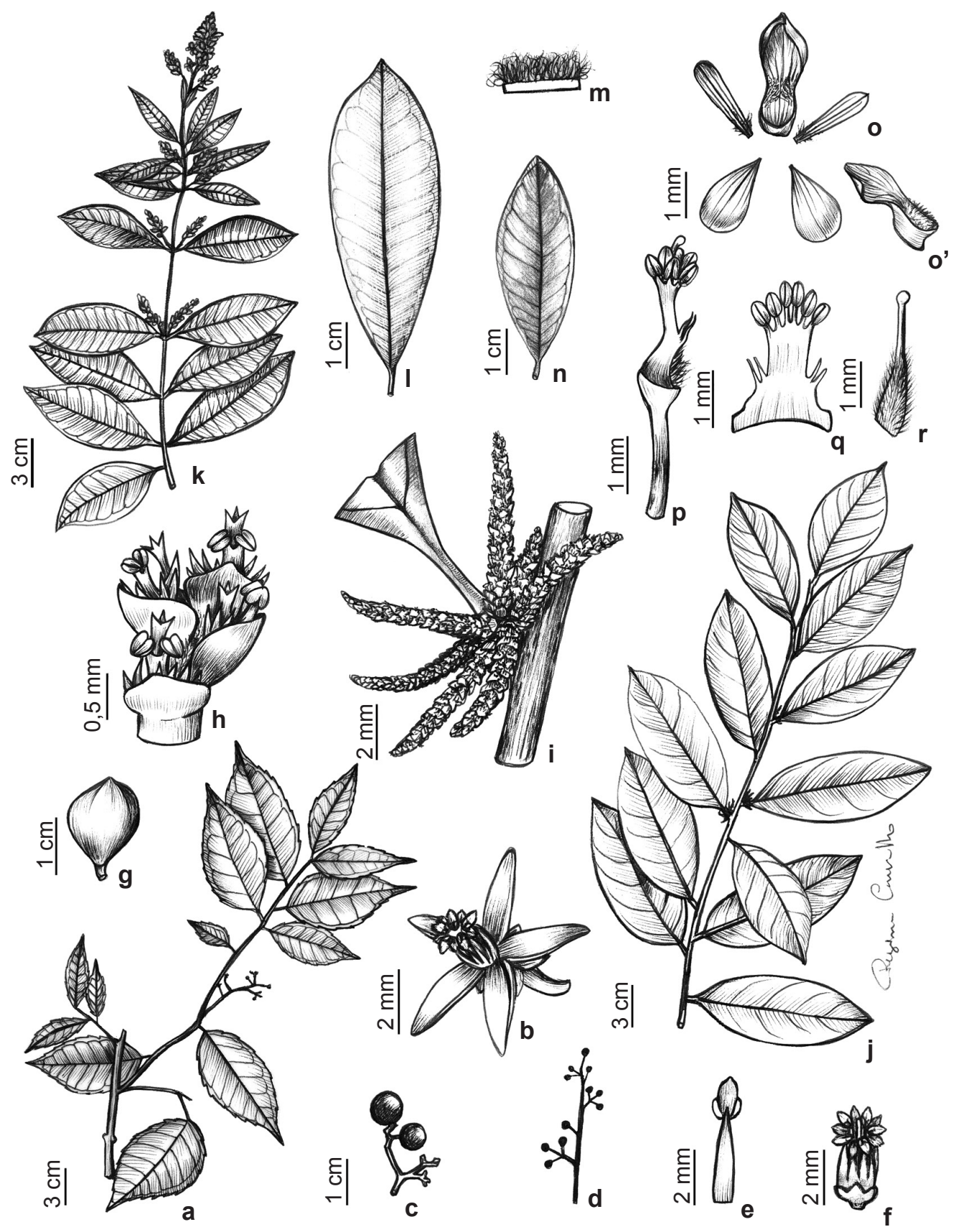

Figura 3 - a-f. Sacoglottis mattogrossensis var. mattogrossensis - a. ramo; b. flor; c. frutos e inflorescência modificada pelo desenvolvimento dos frutos; d. representação esquemática do padrão de crescimento das inflorescências; e. estame com conectivo desenvolvido; f. flor com a corola retirada, portando sépalas e verticilos férteis. g-j. Lacistema robustum g. fruto; h. flores; i. detalhe das inflorescências; j. ramo. k-r. Trigonia nivea var. nivea - k. ramo; 1. face abaxial da folha; m. esquema do indumento da face abaxial; n. face adaxial; o. pétalas, de cima para baixo: estandarte, alas e quilhas; o'. estandarte em visão lateral; p. flor portando apenas os verticilos férteis; q. androceu; r. gineceu.

Figure 3 - a-f. Sacoglottis mattogrossensis var. mattogrossensis - a. branch; b. flower; c. fruits and modified inflorescence by fruit development; d. schematic representation of the inflorescence growth pattern; e. stamen with developed connective; f. flower with corolla removed, bearing only sepals and fertile whorls. g-j. Lacistema robustum - g. fruit; h. flowers; i. inflorescence details; j. branch. k-r Trigonia nivea var. nivea k. branch; 1. lower leaf surface; $m$. illustration of lower leaf surface; $n$. upper leaf surface; o. petals, from top to bottom: standard, wings and keels; $\mathrm{o}^{1}$. standard in lateral view; $\mathrm{p}$. flower bearing only fertile whorls; q. androecium; r. gynoecium. 
glabrescente, abaxial espaçadamente estrigosa, nervação camptódroma, nervuras secundárias glabras na face adaxial e espaçadamente estrigosas a glabras na face abaxial, 6-8 pares, margem inteira, base arredondada a cuneada, ápice acuminado, acúmen $0,5-0,9 \mathrm{~cm}$ compr. Inflorescência espiga, axilar; raque pubescente, marrom quando seca; brácteas e bractéolas $0,05-0,1 \times 0,01-0,08 \mathrm{~cm}$, lineares a suborbiculares, persistentes, glabras, eglandulosas; flores sésseis, eglandulosas; hipanto ausente; sépalas 0,08-0,1 cm compr., lineares, glabras; disco nectarífero na base dos estames; corola ausente, estames 2, exsertos, fusionados até o ápice em forma de $\mathrm{Y}$, estaminódios ausentes; filetes 0,05-0,06 cm compr., glabros; anteras rimosas; ovário $0,03-0,05 \times$ ca. $0,03 \mathrm{~cm}$, orbicular, 1-locular, setoso; 2-3 óvulos; estilete terminal, 0,03-0,04 cm compr., glabro, estigma inteiro. Fruto cápsula, 1-1,3 $\times 0,7-1,3 \mathrm{~cm}$, obovada, epicarpo glabro.

Material examinado: Mata de Piedade, 11.VII.2002, fl., S.G. Freire et al. 70 (NY, PEUFR, UFP).

Material adicional examinado: BRASIL. PERNAMBUCO: Bonito, Reserva Municipal de Bonito, 6.III.1993, fr., M. Lucena et al. 122 (PEUFR). Recife, Mata do Comando Militar do Nordeste, 6.III.1993, fr., A.C.B. Lins e Silva et al. 177 (JPB, PEUFR).

É endêmica da Floresta Atlântica do Brasil, encontrada apenas no estado do Espírito Santo e no Nordeste, nos estados da Bahia e Pernambuco (BFG 2015). Na Usina São José, pode ser encontrada em sítios ripários. É reconhecida entre as espécies da área pelas inflorescências em espiga com raque pubescente, marrom quando seca, e flores monoclamídeas.

Trigoniaceae A. Juss.

Trigonia Aubl.

9. Trigonia nivea Cambess. var. nivea, in A. St.Hil., Fl. Bras. Merid. 2:113. $1829 . \quad$ Fig. 3k-r

Lianas; ramos espaçadamente tomentosos a lanosos, lenticelas conspícuas. Folhas simples, opostas; estípulas 2, interpeciolares, $0,5-0,7 \times$ ca. $0,1 \mathrm{~cm}$, lineares, pubescentes, caducas; pecíolo 0,4-0,9 cm compr., cilíndrico, pubescente a glabrescente, eglanduloso; lâmina foliar 3-10,5 × 1,3-6 cm, oblongo-elíptica, oblanceolada a oblonga, subcoriácea, face adaxial espaçadamente pubescente a glabra, abaxial lanosa de coloração alva, nervação broquidódroma, nervura primária pubescente em ambas as faces, secundárias glabras em ambas as faces, 10-13 pares, margem inteira, base cuneada, obtusa ou atenuada, ápice agudo a arredondado, às vezes mucronado. Inflorescência racemo ou panícula, axilar ou terminal; raque pubescente, amarronzada; brácteas e bractéolas $0,2-0,5 \times 0,04-0,1 \mathrm{~cm}$, lineares, persistentes, seríceas na face adaxial e pubescentes na face abaxial, eglandulosas; flores pediceladas, pedicelo $0,3-0,5 \mathrm{~cm}$ compr., eglanduloso; hipanto ausente; sépalas $0,3-0,4 \mathrm{~cm}$ compr., ovadas a levemente elípticas, glabrescentes na face adaxial, lanuginosas na face abaxial; disco nectarífero na base do ovário; corola papilionácea, diferenciada em estandarte (1), alas (2) e quilhas (2); estandarte $0,4-0,5 \times 0,2-0,3 \mathrm{~cm}$, piloso na face adaxial, glabro na abaxial, calcarado, alas $0,42-0,5 \times 0,1-0,12 \mathrm{~cm}$, pilosas na base, quilhas $0,35-0,4 \times 0,12-0,15 \mathrm{~cm}$, glabras; estames 6 , exsertos, fusionados parcialmente pela base, estaminódios 4 ; filetes $0,18-0,2 \mathrm{~cm}$ compr., filiformes, glabros; anteras rimosas; ovário $0,08-0,1 \times 0,05-0,1 \mathrm{~cm}$, orbicular, 3-locular, piloso, pluriovulado por lóculo; estilete terminal, $0,15-0,2$ $\mathrm{cm}$ compr., piloso na base a glabrescente no ápice, estigma inteiro. Fruto cápsula, 3-5,2 × 0,7-1,8 cm, oblongo a elipsoide, epicarpo velutino.

Material examinado: Mata de Chave, 24.XI.2009, fl., E. Pessoa. \& J.A.N. Souza 171 (UFP); Mata de Pezinho, 28.I.2008, f1., L.M. Nascimento \& G. Batista 627 (UFP); Mata de Piedade, 27.IX.2009, fl., J.D.G. Garcia 1344 (HUEFS, IPA, JPB, NY, UFP); 27.XI. 2009, fl., J.A.N. Souza et al. 570 (ASE, UFP).

Material adicional examinado: BRASIL. PERNAMBUCO: Búque, 10.VII.1997, fr., A. Lacerda et al. (HST10117); 19.VI.1994, fr., A. Miranda 1712 (HST). Belo Jardim, 27.V.1993, fl. e fr., A. Miranda et al. 757 (HST, HUESB). Maraial, 20.V.1996, fr., J. Filho 17 (HST). Vicência, 17.II.1965, fl. e fr., G. Teixeira 2606 (HST).

Ocorre no Brasil, Guiana, Paraguai e Venezuela (Lleras 1978). No Brasil é encontrada em quase todos os estados das regiões Sudeste, no Sul, no Paraná e Santa Catarina, no Centro-Oeste, em Goiás, e no Norte, Acre, Pará e Roraima (BFG 2015). No Nordeste, possui registros da Bahia ao Maranhão (BFG 2015), com um novo registro para o estado de Alagoas (S.O. Santos 259 - JPB, NY, UFP). Na USJ é encontrada frequentemente nas bordas dos remanescentes e em clareiras. É reconhecida pelo hábito lianescente, folhas opostas e corola papilionácea.

\section{Agradecimentos}

À Usina São José, especialmente ao Sr. Lenilson, o apoio logístico durante as coletas; ao $\mathrm{CNPq}$, a bolsa de Mestrado concedida ao primeiro autor; aos curadores dos Herbários visitados, a receptividade durante a consulta às coleções; a Regina Carvalho, as ilustrações; a toda equipe que 
se dedicou às coletas do Projeto de Flora da USJ; aos revisores deste manuscrito, as contribuições.

\section{Referências}

Alves M, Alves-Araújo A, Amorim B, Araújo B, Aráujo D, Araújo MF, Buril MT, Costa-Lima J, GarciaGonzalez J, Gomes-Costa G, Melo A, Novaes J, Oliveira S, Pessoa E, Pontes T \& Rodrigues J (2013) Inventário de angiospermas dos fragmentos de Mata Atlântica da Usina São José, Igarassu, Pernambuco. In: Buril MT, Melo A, Alves-Araújo A \& Alves M (eds.). Plantas da Mata Atlântica: guia de árvores e arbustos da Usina São José (Pernambuco). Editora Livro Rápido, Olinda. Pp.133-158.

Amorim BS \& Alves M (2011) Flora da Usina São José, Igarassu, Pernambuco: Myrtaceae. Rodriguésia 62: 499-514.

Amorim BS, Maciel JR, Melo A \& Alves M (2016) Flora da Usina São José, Igarassu, Pernambuco: Lecythidaceae, Marcgraviaceae e Primulaceae. Rodriguésia 67: 971-979. DOI: 10.1590/21757860201667408.

APG IV (2016) An update of the Angiosperm Phylogeny Group classification for the orders and families of flowering plants: APG IV. Botanical Journal of the Linnean Society: 1-20. DOI: 10.1111/boj.12385.

Ash AW, Ellis B, Hickey LJ, Johnson KR, Wilf P \& Wing S (1999) Manual of leaf Architecture morphological description and categorization of dicotyledonous and net-veined monocotyledonous angiosperms by Leaf Architecture Working Group. Smithsonian Institution, Washington. 65p.

Asprino R \& Amorim AM (2016) Flora da Bahia: Hirtella (Chrysobalanaceae). Sitientibus série Ciências Biológicas 16: 1-20. DOI: 10.13102/ scb1099.

Barroso G (1991) Chrysobalanaceae. In: Barroso GM, Peixoto AL, Ichaso CLF, Costa CG, Guimarães EF \& Lima HC (eds.) Sistemática de Angiospermas do Brasil. Vol. 2. Universidade Federal de Viçosa, Imprensa Universitária, Viçosa. Pp. 15.

BFG - The Brazil Flora Group (2015) Growing knowledge: an overview of seed plant diversity in Brazil. Rodriguésia 66: 1085-1113. DOI: 10.1590/2175-7860201566411.

Bittrich V (2014) Trigoniaceae. In: Kubitzki K (ed.) The families and genera of vascular plants: flowering plants. Eudicots Malpighiales. Vol. 11. SpringerVerlag, New York. Pp. 288-301. DOI: 10.1007/9783-642-39417-1.

Bove CP (1997) Phylogenetic analysis of Humiriaceae with notes on the monophyly of Ixonanthaceae. Journal of Comparative Biology 2: 19-24.

Buril MT \& Alves M (2011) Flora da Usina São José, Igarassu, Pernambuco: Convolvulaceae. Rodriguésia 62: 93-105.
Buril MT, Melo A, Alves-Araújo A \& Alves M (2013) Plantas da Mata Atlântica: guia de árvores e arbustos da Usina São José (Pernambuco). Editora Livro Rápido, Olinda. 162p.

Buril MT, Thomas WW \& Alves M (2014) Flora da Usina São José, Igarassu, Pernambuco: Rutaceae, Simaroubaceae e Picramniaceae. Rodriguésia 65: 701-710. DOI: 10.1590/2175-7860201465309.

Cuatrecasas J (1961) A taxonomic revision of Humiriaceae. Contributions from the United States National Herbarium 35: 25-214.

Ferreira DMC, Amorim BS, Maciel JR \& Alves M (2016) Floristic checklist from an Atlantic Forest vegetation mosaic in Reserva Particular do Patrimônio Natural Fazenda Tabatinga, Pernambuco, Brazil. Check List 12: 2019. DOI: 10.15560/12.6.2019.

Fidalgo O \& Bononi VL (coord.) (1984) Técnicas de coleta, preservação e herborização de material botânico. Instituto de Botânica, São Paulo. 61p.

Flora do Brasil 2020 (2017) Chrysobalanaceae. In: Flora do Brasil 2020 (em construção) Disponível em <http://floradobrasil.jbrj.gov.br/reflora/ floradobrasil/FB48022>. Acesso em 08 setembro 2017.

Guimarães EF \& Miguel JR (1996) Flora da Serra do Cipó, Minas Gerais: Trigoniaceae. Boletim de Botânica 15: 93-96.

Harris JG \& Harris MW (2000) Plant identification terminology, an illustrated glossary. Spring Lake Publishing, Spring Lake. 197p.

Judd WS, Campbell CS, Kellogg EA, Stevens PF \& Donoghue MJ (2009) Sistemática vegetal: um enfoque filogenético. $3^{\mathrm{a}} \mathrm{ed}$. Artmed, Porto Alegre. $632 \mathrm{p}$.

Köppen W (1948) Climatologia. Fondo de Cultura Econômica, México. 496p.

Kubitzki K (ed.) (2014) The families and genera of vascular plants: flowering plants. Eudicots Malpighiales. Vol. 11. Springer-Verlag, New York. 331p. DOI: 10.1007/978-3-642-39417-1.

Lleras E (1978) Trigoniaceae. In: Irwin HS (ed.). Flora Neotropica Monograph 19. Hafner Publishing, New York. 73p.

Luna NKM, Pessoa E \& Alves M (2016) Flora da Usina São José, Igarassu, Pernambuco: Zimgiberales. Rodriguésia 67: 261-273. DOI: 10.1590/21757860201667114.

Marinho LC \& Amorim AM (2015) Flora da Bahia: Lacistemataceae. Sitientibus série Ciências Biológicas 15: 1-6. DOI: 10.13102/scb478.

Melo A, Araújo A \& Alves M (2013) Flora da Usina São José, Igarassu, Pernambuco: Aristolochiaceae e Piperaceae. Rodriguésia 64: 543-553.

Melo A, Amorim BS, Pessoa E, Maciel JR \& Alves M (2016) Serra do Urubu, a biodiversity hot-spot for angiosperms in the northern Atlantic Forest 
(Pernambuco, Brazil). Check List 12: 1842. DOI: $10.15560 / 12.1 .1842$

Pessoa EM \& Alves M (2012) Flora da Usina São José, Igarassu, Pernambuco: Orchidaceae. Rodriguésia 63: $1-16$

Pessoa LM, Pinheiro TS, Alves MCJL, Pimentel RMM \& Zickel RM (2009) Flora lenhosa em um fragmento urbano de Floresta Atlântica em Pernambuco. Revista de Geografia 26: 247-262.

Prance GT (1972) Chrysobalanaceae. In: Irwin HS (ed.) Flora Neotropica Monograph 9. Hafner Publishing, New York. 410p.

Prance GT (1989) Chrysobalanaceae. In: Irwin HS (ed.) Flora Neotropica Monograph 9S. Hafner Publishing Company, New York. 270p.

Prance GT (2003) Chrysobalanaceae. In: Wanderley MGL, Shepherd GJ, Giulietti AM \& Melhem TS (eds.) Flora fanerogâmica do estado de São Paulo. Instituto de Botânica, São Paulo. Vol. 3, pp. 33-44.

Prance GT (2014) Chrysobalanaceae. In: Kubitzki K (ed.) The families and genera of vascular plants: flowering plants. Eudicots Malpighiales. Vol. 11. Springer-Verlag, New York. Pp. 19-28. DOI: 10.1007/978-3-642-39417-1.

Prance GT \& Sothers CA (2003a) Chrysobalanaceae 1: Chrysobalanus to Parinari. In: Orchard AE \& Wilson AJG (eds.) Species plantarum: flora of the World 9. Australian Biological Resources Study, Canberra. 268p.

Prance GT \& Sothers CA (2003b) Chrysobalanaceae 2, Acioa to Magnistipula. In: Orchard AE \& Wilson AJG (eds.) Species plantarum: flora of the world 10. Australian Biological Resources Study, Canberra. $319 p$.

Sá Neto AH \& Lima RB (2003) Flora da Paraíba: família Humiriaceae Juss. Revista Nordestina de Biologia 17: 3-10.

Sacramento AC, Zickel CS, \& Almeida Jr. EB (2007) Aspectos florísticos da vegetação de restinga no litoral de Pernambuco. Revista Árvore 31: 11211130 .
Silva AG, Sá-e-Silva IMM, Rodal MJN \& Lins-e-Silva AC (2008) Influence of edge and topography on canopy and sub-canopy structure of an Atlantic Forest fragment in Igarassu, Pernambuco state, Brazil. Bioremediation, Biodiversity and Bioavaliability 2: 41-46.

Sleumer HO (1980) Flacourtiaceae. In: Irwin HS (ed.) Flora Neotropica Monograph 22. Hafner Publishing, New York. 499p.

Soltis DE, Soltis PS, Chase MW, Mort ME, Albach DC, Zanis M, Savolainen V, Hahn WH, Hoot SB, Fay MF, Axtell M, Swensen SM, Prince LM, Kress WJ, Nixon KC \& Farris JS (2000) Angiosperm phylogeny inferred from $18 \mathrm{~S}$ rDNA, rbcL, and atpB sequences. Botanical Journal of the Linnean Society 133: 381-461. DOI: 10.1006/boj1.2000.0380.

Sothers CA, Prance GT \& Chase MW (2016) Towards a monophyletic Licania: a new generic classification of the polyphyletic Neotropical genus Licania (Chrysobalanaceae). Kew Bulletin 71: 1-68. DOI: 10.1007/s12225-016-9664-3.

Stevens PF (2017) Angiosperm Phylogeny Website. Version 12, July 2012 (and more or less continuously updated since). Disponível em $<$ http://www.mobot. org/MOBOT/research/APweb/>. Acesso em 16 janeiro 2017.

Thiers B [continuamente atualizado] Index Herbariorum: a global directory of public herbaria and associated staff. New York Botanical Garden's Virtual Herbarium. Disponível em $<$ http://sweetgum.nybg. org/science/ih/>. Acesso em 16 abril 2017.

Trindade MB, Lins-e-Silva ACB, Silva HP, Figueira SB \& Schessl M (2008) Fragmentation of the Atlantic Rainforest in the Northern Coastal Region of Pernambuco, Brazil: recent changes and implications for conservation. Bioremediation, Biodiversity and Bioavailability 2: 5-13.

Zickel CS, Almeida Jr. EB, Medeiros DPW, Lima PB, Souza TMS \& Lima AB (2007) Lists of species: Magnoliophyta species of restinga, state of Pernambuco, Brazil. Check List 3: 224-241.

\section{Lista de exsicatas}

Albuquerque NA 208 (3), 219 (3), 543 (3), 630 (3). Alves-Araújo A 821 (3), 856 (7). Andrade-Lima D 33 (2), $69-5595$ (2). Araújo D 177 (3). Barreto R s/n (PEUFR6651) (3). Bezerra GJ 247 (3). Cavalcanti D 37 (3). Costa Lima T 53 (6). Cunha LV 344 (3), 352 (4). Filho J 17 (9). Freire SG 70 (8). Garcia JDG 1344 (9). Gomes JS 44 (5). Gomes-Silva F 237 (3), 238 (3), 239 (3), 255 (3), 256 (1), 257 (5), 258 (4), 259 (3), 300 (6). Irapuan J 17 (3). Lacerda A s/n (HST10117) (9). Leão IV 164 (2). Lins e Silva ACB 305 (3), 177 (8). Lucena HCH 337 (7). Lucena MFA 122 (8), 1135 (1). Melo A 130 (4), 156 (3), 175 (3). Melquíades A 156 (3). Miranda A 757 (9), 1712 (9). Nascimento LM 627 (9), 679 (3). Oliveira APP 87 (7). Oliveira M 1135(1). Oliveira PP 52 (5). Pessoa E 151 (3), 171 (9). Rocha KD 106 (7). Sacramento A 162 (7). Silva HCH 31 (5). Silva IMMS 55 (4), 56 (5), 71 (7), 326 (3). Silva MAM 49 (3). Souza JAN 263 (3), 365 (3), 570 (9). Tavares S 1208 (5). Teixeira G 2573 (5), 2606 (9).

Editor de área: Dr. Gustavo Shimizu Artigo recebido em 09/05/2017. Aceito para publicação em 31/10/2017. This is an open-access article distributed under the terms of the Creative Commons Attribution License. 